\title{
Operação semiótica da categoria gênero: proposta de um modelo teórico-metodológico ${ }^{1}$
}

\author{
Adriana Tulio Baggio' \\ https://orcid.org/0000-0002-5016-1289 \\ I - Pesquisadora independente \\ Curitiba (PR), Brasil.
}

Resumo: Este artigo propõe, a partir da discussão de abordagens teóricas da semiótica discursiva e dos estudos de gênero, um modelo para análise da categoria gênero em textos e discursos, tomando por base o quadrado que estrutura as relações fundamentais de significação. Para sustentar a proposta, o texto apresenta conceitos como a diferença entre identidade e expressão de gênero e a não estabilidade das identidades normativas "mulher" e "homem"; mostra a pertinência de se considerar feminino e masculino como temas constituídos por figuras de conteúdo e de expressão; resgata e faz a crítica de quadrados semióticos de gênero e sexualidade publicados em textos canônicos. O modelo, que se pretende de operação geral, apresenta quatro modos de articulação entre feminino e masculino, que compreendem quatro áreas em que as mais diversas identidades de gênero podem se situar: bigeneridade, ageneridade, supermasculinidade e superfeminilidade.

Palavras-chave: semiótica do gênero; quadrado semiótico; identidade de gênero; temas e figuras; axiologia.

Abstract: Semiotic operation of the gender category: proposal for a theoretical-methodological model - This paper discusses theoretical approaches of discursive semiotics and gender studies and proposes a model for the analysis of the gender category in texts and discourses, based on the square that structures the fundamental relations of meaning. To support the proposal, the work presents concepts from gender studies, such as the difference between identity and expression and the non-stability of the normative identities "woman" and "man"; it shows the pertinence of considering feminine and masculine as themes constituted by content and expression figures; it rescues and discusses semiotic squares of gender and sexuality published in canonical texts. The model, which is intended for general operation, presents four modes of articulation between the terms feminine and masculine, which comprise four

1 Versão inédita em português de trabalho originalmente publicado em francês nos anais do Congrès de I'Association Française de Sémiotique, realizado em Paris em 2017 (BAGGIO, 2019). 
areas in which the most diverse gender identities can be located: bigenderity, agenderity, super masculinity, and super femininity.

Keywords: gender semiotics; semiotic square; gender identity; themes and figures; axiology.

\section{Proposta}

Dentre outras coisas, gênero designa um campo multidisciplinar que investiga as relações sociais entre os sexos, cujos estudos buscam especialmente "[...] dar conta da existência da opressão de diversas naturezas postas na história" (MURARO, 2011, p. 9). Ambicionando integrar campo já tão vasto, este trabalho discute conceitos de gênero e da semiótica e, com base neles, propõe um modelo teórico-metodológico para análise da categoria gênero em textos e discursos. O modelo se estrutura a partir do quadrado semiótico - que organiza as relações elementares de significação — elaborado por Algirdas Julien Greimas e François Rastier (1975).

A contribuição se justifica por, talvez, conseguir superar certas limitações identificadas nos estudos de gênero e na semiótica. Judith Butler (2003, p. 12), por exemplo, entende que "[a] complexidade do conceito de gênero exige um conjunto interdisciplinar e pósdisciplinar de discursos, com vistas a resistir à domesticação acadêmica dos estudos sobre o gênero ou dos estudos sobre as mulheres [...]". Aumentar a participação da semiótica entre esses discursos pode ser uma forma de neutralizar tal domesticação, e, deles, efetivamente a semiótica e a semiologia não estão ausentes, pois tanto Butler (2003) quanto Raweyn Connell (1997), nas obras aqui citadas, referenciam autores dessas áreas.

Há uma crítica, porém, quanto ao tratamento dado ao gênero pelas disciplinas da significação. A teoria feminista (da qual se originam os estudos de gênero) reconhece a utilidade da semiótica estruturalista, mas entende que nem sempre ela dá conta de tratar das relações de poder na constituição das diferenças, tais como aquelas associadas a certas formas de subordinação e de dominação patriarcal (FRANKLIN; LURY; STACEY, 1997). A própria Butler (2003, p. 28) também faz sua ressalva. Para a filósofa, os limites da análise discursiva do gênero "[...] pressupõem e definem por antecipação as possibilidades das configurações imagináveis e realizáveis do gênero na cultura". E com isso pode-se estar de acordo: há muito mais configurações de gênero do que aquelas designadas por mulher e homem, par axiológico normalmente operado a priori nas análises. Por outro lado, como se verá adiante, mesmo as identidades que a recusam ou que vão além dessa classificação canônica são baseadas em alguma articulação entre feminino e masculino.

Parece então que o problema está 1) na classificação predeterminada e 2) na diferença de valor de cada identidade, mas não propriamente na operação do gênero, categoria que, independentemente da nossa vontade, tem até agora organizado as relações no mundo. Com base nessas premissas, nas próximas seções propõe-se que a semiótica discursiva, especialmente a partir do modelo lógico do quadrado, pode dar conta de certas 
abordagens e objetivos dos estudos de gênero, como aqueles que pretendem verificar a presença e a valoração positiva ou negativa dos temas feminino e masculino em diversos objetos de análise.

Tal modelo, por seu caráter de generalização, teria condições de apreender os efeitos de sentido das identidades, tanto das canônicas quanto das divergentes (assim chamadas por divergirem das normas da matriz heterossexual, apresentada a seguir), que se manifestam nos textos e nas práticas sociais, sem o inconveniente de resvalar em eventuais armadilhas de classificação.

\section{O gênero como construção e como sistema de relações não unívocas}

Uma visão conservadora da relação entre sexo e gênero considera que os pares dessas duas categorias são homologáveis e unívocos. Butler (2003, p. 216) denomina essa "grade de inteligibilidade cultural" como "matriz heterossexual". A matriz presume que os corpos devem apresentar uma coerência entre sexo, identidade de gênero e expressão de gênero; que essas categorias são estáveis; e que as relações afetivo-sexuais acontecem obrigatoriamente entre pessoas de sexos opostos.

Nesse contexto, a categoria do sexo é formada pelo par fêmea e macho; a categoria identidade de gênero, por mulher e homem; e a categoria expressão de gênero, por feminino e masculino. Há, obviamente, outras possibilidades nos eixos horizontais², mas a matriz não as vê como naturais. Pela lógica da matriz, uma pessoa identificada com o sexo macho no nascimento deverá obrigatoriamente assumir a identidade homem e expressar um parecer (organização corporal, gestos, cabelos, roupas, comidas preferidas, profissão etc.) masculino; a mesma homologação deve ocorrer entre fêmea, mulher, feminino.

Apesar de a matriz não considerar outras combinações e orientações sexuais, elas existem e constituem identidades nomeadas especificamente em situações nas quais a sua individuação e caracterização são desejáveis ou necessárias (por exemplo, na atribuição de gênero no perfil da rede social Facebook, no ativismo, na elaboração de políticas públicas). Ao mesmo tempo, teóricos e militantes discutem a dificuldade e os problemas de se definir e classificar as identidades de gênero, tanto as canônicas como as divergentes. Letícia Lanz (2015, p. 365), pesquisadora dos estudos transgêneros, pensa que tais processos de definição e classificação "[...] têm servido [ao menos no Brasil] muito mais como mecanismos de opressão do que como estratégias libertárias [...]".

Na prática, mesmo pessoas que não se identificam com as categorias binárias ${ }^{3}$ de gênero usam elementos dessas categorias para se autodenominar ou autoidentificar.

2 Para uma explicação didática dessas categorias e de seus elementos, ver The Genderbread Person (KILLERMANN, 2017).

3 Pode-se chamá-las de pessoas transgêneras, na medida em que transgênera é um adjetivo que qualifica a pessoa que diverge das normas socialmente aceitas e sancionadas para a categoria gênero (LANZ, 2015, p. 69). Em oposição, a pessoa que expressa conformidade a essas normas é qualificada de cisgênera. 
É o caso da cantora austríaca Conchita Wurst (figura 1), personagem criada e incorporada por Thomas Neuwirth e descrita por ele, certa vez ${ }^{4}$, como "uma mulher com barba" (CONCHITA, 2017, grifos meus). Incorporando objetivos políticos aos artísticos — lutar contra a discriminação e discutir ideias sobre diferença e normalidade —, o artista seleciona e atualiza, em uma combinação não normativa, figuras dos paradigmas do feminino e do masculino, questionando os simulacros de mulher e de homem.

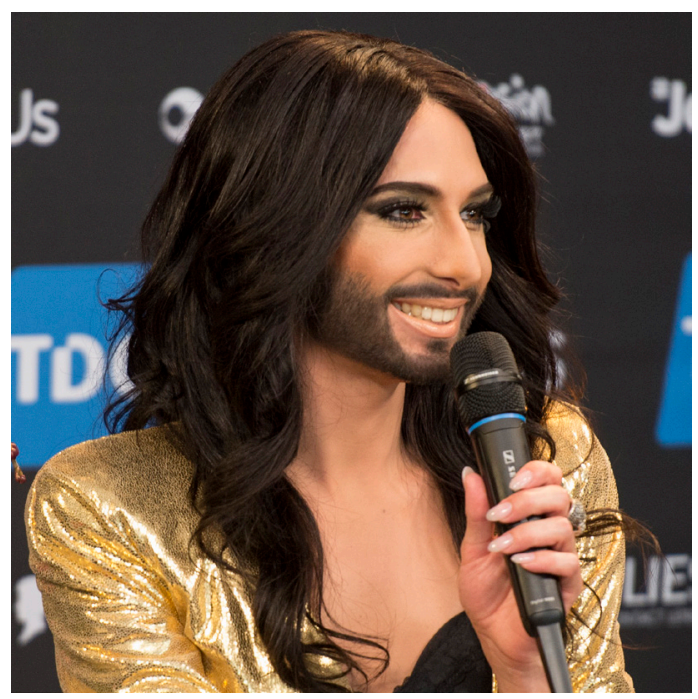

Fig. 1. Conchita Wurst, conjuga os dois gêneros. Fonte: OLSSON, A. Conchita Wurst, ESC2014 Meet \& Greet 08. 30 Abr. 2014. Licença CC BY-SA 3.0. Disponível em: https://commons.wikimedia.org/wiki/File:Conchita_Wurst,_ESC2014_Meet_\%26_Greet_08_ (crop).jpg. Acesso em: 22 Abr. 2020.

Enquanto Neuwirth mescla as figuras e quer que elas sejam reconhecidas, a personagem Taylor Mason (figura 2), da série Billions, vivida por Asia Kate Dillon (pessoa de gênero não binário na "vida real"), busca justamente o oposto: negar esse binarismo. Taylor não se identifica nem com o gênero feminino nem com o masculino ${ }^{5}$; pede para que usem com ela os pronomes da terceira pessoa do plural - they, them, their - que, no inglês, são de gênero gramatical neutro (LA (NON)-REPRÉSENTATION, 2018).

4 Hoje, a personagem de Thomas Neuwirth está desdobrada em duas figuratividades, Conchita (feminina) e Wurst (masculina), que realizam performances musicais e midiáticas de estilos diferentes (CONCHITA, 2019).

5 No entanto, ao se observar as roupas que veste e sua configuração corporal, a personagem constitui um enunciado cuja isotopia figurativa materializa predominantemente o tema do masculino. Tem-se, portanto, a contraposição de dois textos distintos: o discurso da autoidentificação, manifestado em texto verbal, e o discurso manifestado pelas roupas e pelo corpo, cujas figuras dificilmente conseguem escapar da generificação binária. 


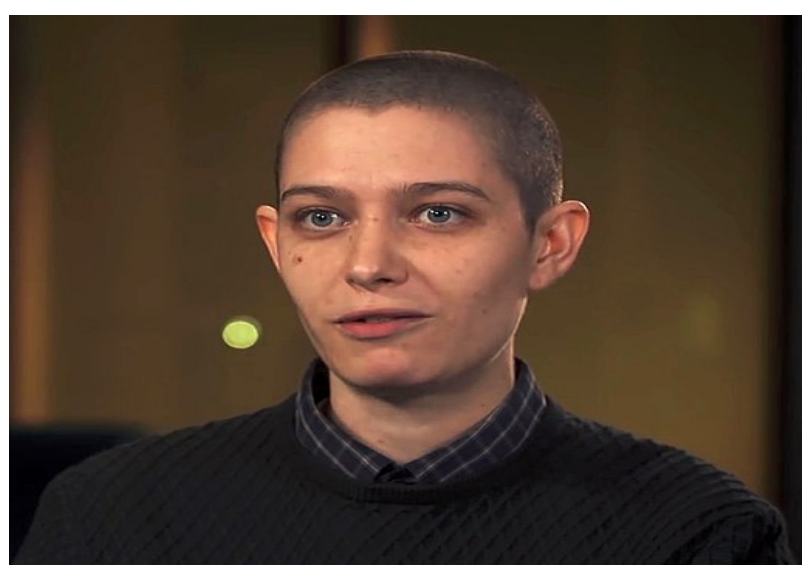

Fig. 2. Taylor Mason, nega os dois gêneros. Fonte: BILLIONS. Meet Taylor Mason (Asia Kate Dillon) | Billions | Season 2. 8 jan. 2017. Impressão de tela aos 1'27" do vídeo. Licença CC BY. Disponível em: https://commons.wikimedia.org/wiki/File:Meet_Taylor_Mason_(Asia_Kate_Dillon)_Billions_Season_2.jpg. Acesso em: 22 Abr. 2020.

Ocorre que as manifestações de identidades divergentes desestabilizam a univocidade entre as figuras de expressão de gênero e suas correspondentes normativas de identidade de gênero. Aquilo que se considera como feminino ou masculino não pertence, de forma ontológica ou inerente, exclusiva e respectivamente à mulher e ao homem. Pode-se encontrar o masculino nas mulheres e o feminino nos homens, mesmo nas identidades canônicas. Dessa perspectiva, gênero é uma construção discursiva e cultural, e não natural e predeterminada. E, de uma visada semiótica, feminino e masculino, como os dois elementos constitutivos da categoria gênero, podem ser entendidos como temas compostos por figuras e se manifestam em qualquer tipo de identidade.

Tais princípios estão na base da concepção de Connell (1997, p. 35), para quem "[o] gênero é uma forma de ordenamento da prática social [...] que constantemente se refere aos corpos e ao que os corpos fazem, mas não é uma prática social reduzida ao corpo". E, ainda, que as ações e as práticas de gênero "[...] se configuram em unidades maiores, e quando falamos de masculinidade e feminilidade estamos nomeando configurações de práticas de gênero" (ibidem). Por isso, "[e]ncontramos a configuração generificada da prática em qualquer forma por meio da qual se decida dividir o mundo social e em qualquer unidade de análise que venhamos a selecionar" (ibidem, p. 36).

Se o gênero ordena o mundo social, faz sentido que os elementos dessa categoria sejam utilizados mesmo pelas identidades divergentes.

\section{Uma crítica de certas operações das categorias de gênero e sexualidade na semiótica}

Articular aspectos da sexualidade no modelo do quadrado não é uma novidade na semiótica discursiva. Greimas e Rastier (1975, p. 133) o fazem justamente quando propõem 
tal modelo. Para exemplificar o investimento de conteúdo na estrutura lógica e os valores sociais que manifestam, os autores articulam relações sexuais prescritas e interditas no contexto da sociedade tradicional francesa (figura 3). O amor conjugal seria um exemplo de investimento da relação prescrita (c1); o adultério do homem, uma relação normal e não interdita (c2'); o adultério da mulher, uma relação não matrimonial e não prescrita $\left(\mathrm{c} 1^{\prime}\right)$. Já as relações "anormais" e interditas (c2) seriam a homossexualidade e o incesto.

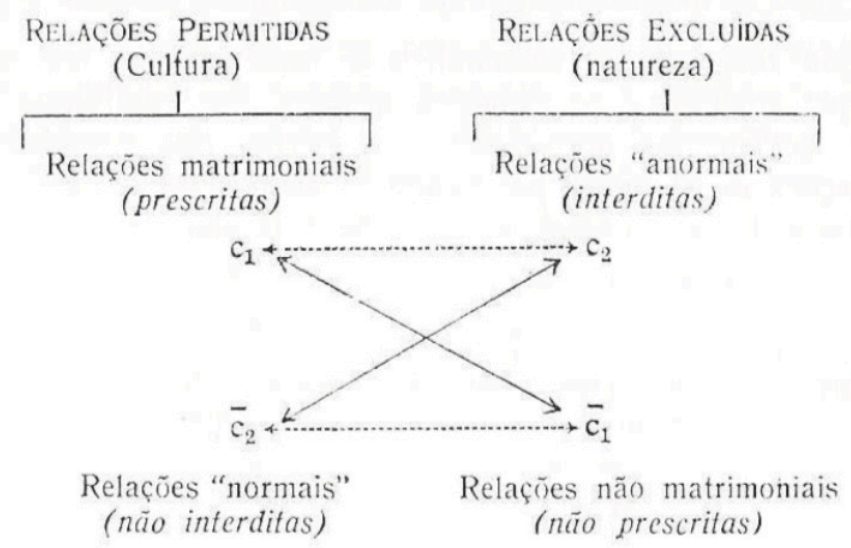

Fig. 3. O quadrado do modelo social das relações sexuais de Greimas e Rastier. Fonte: Greimas e Rastier (1975, p. 133).

Uma abordagem dos estudos de gênero para os investimentos desse modelo aponta a ocorrência de uma "violência semântica" (FIORIN, 2000, p. 19), ou seja, a articulação de elementos de categorias diferentes no mesmo eixo. O quadrado das relações sexuais acaba colocando em oposição elementos que não fazem parte do mesmo paradigma: homossexualidade presume orientação sexual, incesto presume relação de parentesco, matrimônio presume a condição jurídica de uma relação. Casamentos podem ser entre pessoas do mesmo sexo, relações incestuosas podem ser homossexuais, relações heterossexuais permitidas podem não ser juridicamente estabelecidas ${ }^{6}$.

Jean-Marie Floch (1985) também utilizou um quadrado de categorias sexuais (ou de gênero) para ilustrar a axiologização no nível fundamental do percurso gerativo de sentido. No seu diagrama (figura 4), a articulação é entre masculino e feminino, o que gera as posições não masculino e não feminino. O autor ainda investe de conteúdo os termos simples da categoria (masculino $=$ homem, feminino $=$ mulher) e os termos complexos constituídos pela coexistência dos elementos em relação de oposição (masculino + feminino = hermafrodita, não masculino + não feminino = anjo).

6 A manifestação dessa "violência semântica" implica uma visão de mundo, levada a cabo pela enunciação, que os estudos de gênero procuram desnaturalizar. Apontar essas questões não invalida a teoria semiótica, mas visa a mostrar como a disciplina é útil para analisar os conceitos de gênero e sexualidade que organizam uma determinada sociedade - até mesmo quando é operada em seus próprios textos constitutivos. 


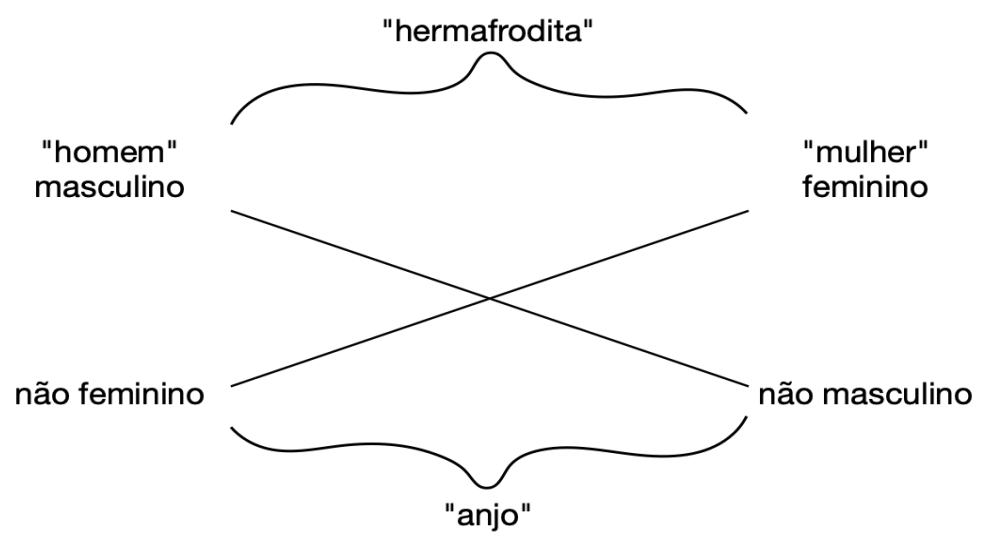

Fig. 4. O quadrado da categoria da sexualidade de Floch. Fonte: adaptado de Floch (1985, p. 199).

Floch faz notar que

[...] os quatro estados sexuais posicionados não correspondem, de fato, aos quatro termos do quadrado. Compreende-se que "mulher" e "homem" manifestam os contrários feminino e masculino. "Hermafrodita" e "anjo" manifestam, por sua vez, neste microuniverso semântico que o quadrado articula, os termos complexos nos quais coexistem os contrários (segundo a racionalidade dos mitos). Quanto aos termos não masculino e não feminino, chamados subcontrários, se eles estão logicamente presentes e então são previsíveis no microuniverso da sexualidade, eles podem muito bem não estar manifestados em uma ou outra língua ou cultura particular (FLOCH, 1985, p. 200, grifos no original).

Evidentemente, a operação do quadrado em um texto específico pode resultar na figura homem como manifestação do masculino e na figura mulher como manifestação do feminino. Mas essa univocidade não pode ser generalizada e nem considerada aprioristicamente.

A enunciação identitária da cantora brasileira Pabllo Vittar ilustra essa questão. Pabllo, de nome masculino, pede para ser chamada de cantora, mas esclarece que não é uma mulher transexual: é um menino gay que faz drag (VITTAR, 2017). Portanto, se formos situar a artista em pontos específicos das categorias sexo, identidade, expressão de gênero e orientação sexual, podemos entendê-la respectivamente como macho (seu sexo biológico), homem (pois se diz "menino"), feminina (pronome e desinência de gênero gramatical feminino que pede para usarem com ela) e homossexual (relaciona-se afetiva e sexualmente com o mesmo sexo). Em Pabllo Vittar, portanto, homem não pode ser 
um investimento de conteúdo pertinente, em relação simbólica e unívoca, para o termo masculino. A relação entre os termos das diversas categorias será bem mais complexa.

Outro problema do quadrado da figura 4 está nos termos complexos que dariam conta da coexistência dos contrários e dos subcontrários nos mitos. Floch (1985) esclarece que, nesse microuniverso, masculino/feminino dá origem ao termo hermafrodita, e não masculino/não feminino dá origem a anjo. Porém, na medida em que o autor investe os termos como homem e mulher, o microuniverso já se expande para além dos mitos e desce ao mundo natural, onde efetivamente existem pessoas intersexo (este termo substitui hermafrodita, considerado pejorativo), ou seja, aquelas que nascem com marcadores (genitais, gônadas, hormônios) dos dois sexos. Como a própria explicação já revela, trata-se, portanto, de um termo da categoria sexo, e não da categoria identidade e nem da categoria expressão de gênero.

Ainda um ponto crítico nesses investimentos semânticos é a ideia de que as identidades de gênero são naturais. Ela aparece quando o autor faz uma consideração didática muito importante sobre a operação do modelo: a de que um quadrado semiótico organiza um universo homogêneo, no qual todos os termos devem pertencer ao mesmo plano (FLOCH, 1985, p. 200). Nesse sentido, não seria possível escolher a palavra ou o estado de eunuco para manifestar o termo contraditório não masculino, pois o quadrado organiza estados naturais ${ }^{7}$ de sexualidade; o eunuco, pela mutilação, estaria no plano dos estados produzidos pelo homem — ou seja, no plano cultural.

Adotando a perspectiva, como feito até aqui, de que o gênero é uma construção discursiva, o quadrado todo de Floch estaria no plano da cultura, e não no plano da natureza, mesmo sem a presença do eunuco. Para Butler (2003, p. 48), nada do que se convoca para classificar alguém como homem ou mulher, masculino ou feminino, é pré-discursivo: "[...] não há identidade de gênero por trás das expressões do gênero; essa identidade é performativamente constituída, pelas próprias 'expressões' tidas como seus resultados.

Em outras palavras, as marcas (ou figuras) — os atos das pessoas, seus gestos, seus desejos - que associamos a cada um dos gêneros canônicos parecerem manifestar um eventual princípio original e organizador das identidades, que seria a causa da presença ou ausência dessas marcas nos corpos. Esse princípio, no entanto, não existe; é simulado pela naturalização das marcas como algo ontológico, que emanaria da essência das pessoas. As marcas são, na verdade, a própria fabricação dessas identidades, daí a ideia de performatividade proposta por Butler:

7 A ideia de "natural" também parece incoerente na medida em que o autor, pouco antes, definiu seu plano semântico como sendo o microuniverso dos mitos. 
O fato de o corpo gênero ser marcado pelo performativo sugere que ele não tem status ontológico separado dos vários atos que constituem sua realidade. Isso também sugere que, se a realidade é fabricada como uma essência interna, essa própria interioridade é efeito e função de um discurso decididamente social e público, da regulação pública da fantasia pela política de superfície do corpo, do controle da fronteira do gênero que diferencia interno e externo e, assim, constitui a "integridade" do sujeito (BUTLER, 2003, p. 194-195, grifos no original).

Por essa lógica, nem mesmo o sexo biológico seria determinante ontológico. Obviamente, os genitais, as gônadas, os hormônios e os cromossomos existem. Mas o papel, a função e as interpretações que se confere a eles na identidade de gênero são discursivos, bem como a valoração de cada tipo de sexo (BUTLER, 2003, p. 166-167).

A ideia de performance também diz respeito à exigência de se manifestar o gênero constantemente para que ele mantenha seu fantasioso status de consequência do princípio interno organizador da identidade. Mesmo a uma pessoa que se autoidentifique com o sexo/ gênero a ela atribuído ao nascer, e que tenha esse sexo/gênero atestado em um documento oficial de identidade, não basta afirmar "sou homem" ou "sou mulher" e depois comportar-se como bem entender. A lógica performativa do gênero cobra que, continuamente, a pessoa manifeste atos, gestos e desejos que sua comunidade associa ao gênero por ela informado, inclusive no que diz respeito ao realce ou ao apagamento de marcas corporais "naturais". O gênero e as suas identidades são fabricados justamente enquanto são performatizados — colocados em ato —, daí o seu caráter eminentemente discursivo.

\section{O que pode fazer uma análise semiótica do gênero}

Os exemplos e conceitos apresentados até agora mostram que masculino e feminino são temas cujas figuras podem ou não aparecer nas identidades tradicionais homem e mulher; que tais identidades manifestam figuras tanto de um quanto de outro tema; e que existem diferentes combinações das figuras desses temas, a ponto de não serem suficientes as classificações homem e mulher. Diante disso, talvez as identidades precisem ser consideradas não como investimentos de termos simples em um quadrado semiótico, mas como termos complexos em que coexistem os dois elementos do eixo semântico de gênero, estejam eles em relação de oposição ou de complementariedade. Isso vale, inclusive, para as identidades tradicionais.

A própria operação da estrutura do quadrado nas relações de gênero já realiza investimentos semânticos (ou de conteúdo), entendidos como valores sociais (GREIMAS; RASTIER, 1975, p. 133). Os termos não têm em si um valor objetivo, ou seja, absoluto; a valoração positiva ou negativa de cada termo vai depender do microuniverso em que o modelo é operado. Isso é especialmente produtivo para verificar o que efetivamente é eufórico ou disfórico naquilo que envolve gênero e sexualidade. Por exemplo: os efeitos de sentido da homossexualidade. 
Mesmo onde a homossexualidade é aceita e legalmente permitida, são frequentes os episódios de discriminação e violência, especialmente contra homossexuais masculinos. Quais os valores em jogo na situação em que algo aceito juridicamente é rejeitado culturalmente? Para Connell (1997, p. 41), “[...] do ponto de vista da masculinidade hegemônica, a homossexualidade se associa facilmente à feminilidade. E por isso - de acordo com o ponto de vista de alguns teóricos homossexuais - a ferocidade dos ataques homofóbicos". Se for assim, a disforia da homossexualidade deve-se especialmente à valoração negativa do feminino que se percebe ou se infere no homem gay.

Considerando que os sistemas de valores de uma sociedade são inventados ou descritos por ela, Greimas e Rastier (1975, p. 141-142) propõem que se chame de episteme "[...] a estrutura que define a hierarquia dos sistemas semióticos em presença. Ela comanda as combinações que podem se encontrar manifestadas". E, ainda, que "[a] episteme dá conta da historicidade das manifestações; sua componente social aparece como um senso comum, implícito ou não, um sistema axiológico e dialético imanente a todas as estruturas semióticas da sociedade considerada".

Voltando à explicação de Connell (1997), pode-se pensar a valoração negativa do feminino como manifestação de uma episteme ou de um senso comum operando acima da pretensa equidade de gênero que, em teoria, estaria garantida pela lei e pelas instituições dessas sociedades.

\section{O quadrado semiótico do gênero: a relação entre expressões $\mathbf{e}$ identidades de gênero}

O quadrado semiótico do gênero proposto neste artigo (figura 5) parte da articulação masculino/feminino realizada por Floch (1985), mas difere desta na projeção da coexistência dos termos. Também difere por não considerar as identidades como investimentos dos termos simples (esses seriam as expressões de gênero), e sim como investimentos dos termos complexos. Tal decisão baseia-se no princípio de que as figuras que compõem cada gênero podem estar presentes em todas as pessoas. As figuras podem variar de acordo com cada época, espaço, sociedade, cultura, classe social. Variam ainda, de pessoa para pessoa, a quantidade e distribuição de figuras de cada tema. Algumas apresentarão mais figuras do tema masculinidade, outras mais figuras do tema feminilidade, e há aquelas que terão uma presença equilibrada de figuras destes dois temas/gêneros.

Se essa ideia talvez pareça radical para as concepções ocidentais de gênero, ela é bastante comum em outras sociedades. A antropóloga Marilyn Strathern (2006, p. 192) observa que os moradores das sociedades melanésias das Terras Altas “[...] não concebem axiomaticamente as pessoas tendo um sexo único. Ao invés disso, o que se manifesta é uma alternância de condições sexuais, dois modos de constituição de gênero. [...] Uma identidade do mesmo sexo, assim, é efetuada como uma invenção deliberada". 
Portanto, se há algo de masculino e feminino em todas as pessoas, ainda que com distribuição variada, uma identidade homem não pode estar associada somente ao termo masculino, da mesma forma que mulher não pode corresponder apenas ao feminino. Tais identidades precisam estar contempladas na área do quadrado representada pela coexistência dos dois termos.

Normalmente, os quadrados representam a relação entre o termo complexo e os termos simples como um triângulo, sendo o eixo destes últimos a base, e aquele o vértice. Neste quadrado de gênero (figura 5), propõe-se que o termo complexo gere um trapézio. Essa representação permite situar as identidades de cada um desses grupos em pontos mais próximos ou mais afastados do termo simples predominante (se houver) em sua expressão. Com isso, a representação dá conta dos diversos tipos de distribuição do masculino e do feminino que ocorrem em cada pessoa e em cada identidade.

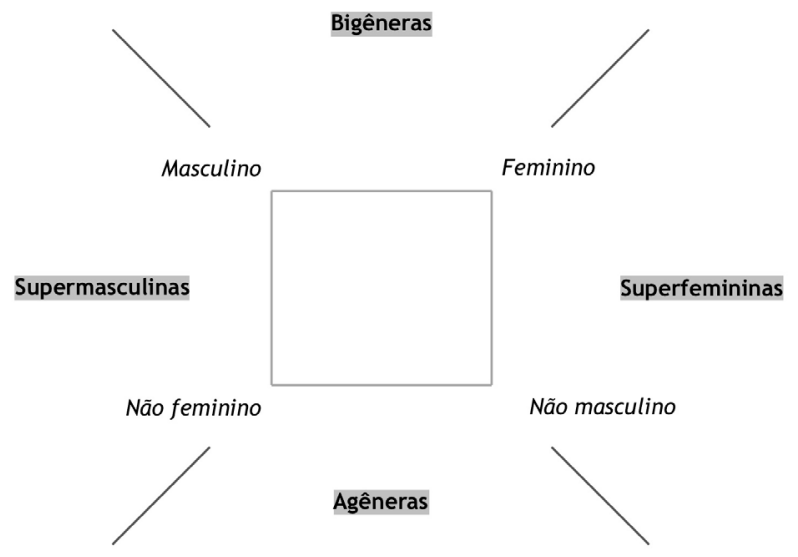

Fig. 5. O quadrado semiótico do gênero.

Fonte: elaborado pela autora.

O primeiro trapézio seria constituído pela coexistência do masculino e do feminino, resultando em identidades bigêneras. Segundo a proposta deste trabalho, entrariam nesse grupo as identidades de Conchita Wurst (em 2017) e Pabllo Vittar. Enquanto o criador da primeira a define como uma "mulher com barba", a segunda se autoidentifica com pronomes femininos, nome masculino e identidade "menino". Ou seja, ambos os enunciados apresentam figuras dos dois temas. As identidades canônicas homem e mulher também seriam classificadas como bigêneras, tanto porque mesmo pessoas cisgêneras manifestam figuras do gênero oposto ao qual se identificam quanto pela inspiradora concepção dos melanésios: a de que "afirmações de completa masculinidade ou de completa feminilidade são definições transitórias e temporárias de poder" (STRATHERN, 2006, p. 192). 
Ainda que entendidos como bigêneros, esses exemplos diferem bastante entre si em termos do parecer construído por suas expressões de gênero. Para contemplar tais diferenças em relação à quantidade de figuras de cada gênero presente em cada identidade, elas devem ser distribuídas de maneira distinta no trapézio: algumas mais próximas do termo simples masculino, outras mais próximas do feminino.

O eixo paralelo oposto, o da não significação, também forma um trapézio a partir da coexistência do não masculino e do não feminino, na medida em que, recordando Greimas e Rastier (1975, p. 131), "[t]odo sistema comporta, por definição, um conjunto de regras; elas se definem positivamente, mas podemos, também, defini-las negativamente pelo que elas não são [...]". De fato, a personagem Taylor Manson, da série Billions, apresenta uma identidade que se define pela negação do gênero. Vale notar, como já assinalado, que uma análise da construção do sentido daquilo que é tido como de gênero neutro mostra, frequentemente, a negação do feminino - como é, de fato, a aparência de Taylor Mason - , e isso enseja diversas outras reflexões. No entanto, como a proposta é levar em conta não apenas a expressão que constitui o parecer do sujeito, mas também outros enunciados sobre a sua identidade, Taylor pode ser alocada neste grupo denominado de agênero: ela se define como nem masculina, nem feminina.

A coexistência de termos em relação de complementaridade também origina grupos de identidades; formadas pela asserção de um gênero e a negação do outro, são entendidas como representativas do processo de exacerbação da performance de gênero. A dragqueen (figura 6) é um exemplo da articulação entre feminino e não masculino, na medida em que sua paródia baseia-se na construção de um parecer saturado de figuras que compõem o feminino. Pessoas que se identificam como mulher e performatizam os simulacros mais conservadores de feminilidade (por exemplo, as imagens de donas de casa na publicidade estadunidense dos anos 1950) também podem estar nesse grupo, o das identidades superfemininas.

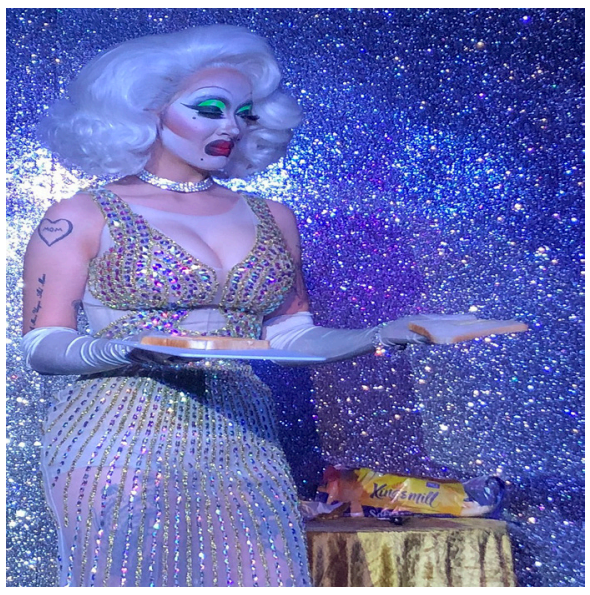

Fig. 6. A artista e dragqueen victoria sin, exemplo de superfeminilidade. Fonte: FRASER, J. Female drag queen and artist Victoria Sin performs on 12th May 2018 at Live Art Bistro, Leeds. 12 Mai. 2018. Licença CC BY-SA 4.0. Disponível em: https://commons. wikimedia.org/wiki/File:Victoria_Sin,_Leeds.jpg. Acesso em: 22 Abr. 2020. 
Oposto a esse, o grupo supermasculino (figura 7) dá conta das identidades que afirmam o masculino e negam o feminino, e são propostas por certas definições normativas de masculinidade, que oferecem um modelo do que os homens deveriam ser (CONNELL, 1997, p. 34); seu simulacro se manifesta, por exemplo, em personagens representados por atores como Humphrey Bogart, John Wayne e Clint Eastwood. Caracterizados pela rudeza, força, liderança e recusa de qualquer aspecto da ordem do feminino, esses seriam exemplos do cianótipo (reproduções em azul) da masculinidade da nossa cultura (BRANNON, 1976 citado por CONNELL, 1997). No entanto, acrescenta Connell (1997), poucos homens conseguem se adequar perfeitamente a tal simulacro. Nessa medida, a conjunção entre modelos de masculinidade oriundos da ficção e a dificuldade que homens reais têm de performatizar essa masculinidade são fatores que sugerem, assim como ocorre com a drag para o feminino, uma paródia do masculino.

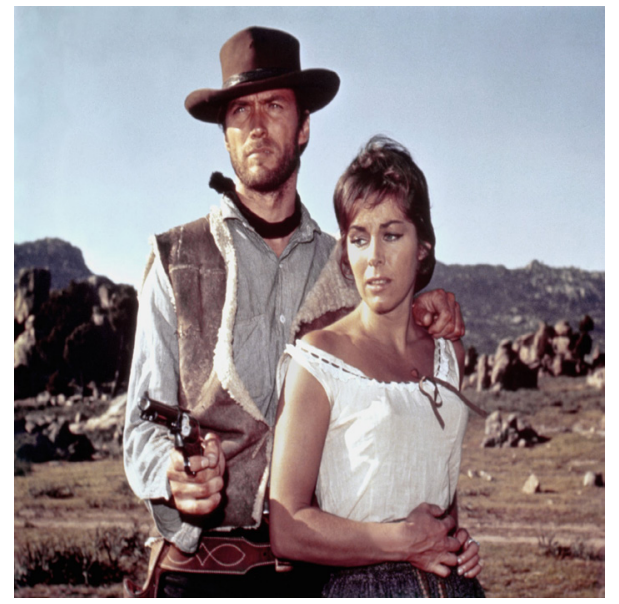

Fig. 7. Clint Eastwood, exemplo de supermasculinidade. Fonte: JOLLY FILME. Clint Eastwood and Marianne Koch in "A Fistful of Dollars", directed by Sergio Leone. 1964. Domínio público. Disponível em: https://upload.wikimedia.org/wikipedia/commons/7/7b/ Clint_Eastwood_and_Marianne_Koch_in_\%22A_Fistful_of_Dollars\%22_\%281964\%29.jpg. Acesso em: 22 Abr. 2020.

A operação do modelo possibilita o estudo das identidades de gênero a partir de dois aspectos envolvidos em sua classificação: a autopercepção e a percepção do outro. Essa última se baseia principalmente nas expressões de gênero manifestadas pela pessoa. A dualidade desse processo fica clara no depoimento do crossdresser Bel F. reproduzido por Lanz (2015, p. 183) em seu livro: “Uma perspectiva é a do próprio indivíduo, como eu estou me percebendo. Outra, é a perspectiva externa de como eu sou percebido. Elas estão interligadas e, para que eu me perceba como mulher, eu tenho que ser percebida, porque o gênero é reiterado a todo momento [... $]^{\prime \prime}$.

O modelo, portanto, não desconsidera as autoidentidades, mas as acolhe junto a outras manifestações enunciadas. Com isso, busca-se evitar a classificação e 
categorização prévia; o que quer que seja analisado pelo prisma de gênero, vai ser sempre considerado como enunciado que manifesta uma combinação entre masculino e feminino em suas relações de oposição, de contraditoriedade e de complementaridade. Isso se justifica, como se deve lembrar, porque estes dois termos são convocados mesmo pelas identidades divergentes e pela constatação da primazia desta categoria na organização do nosso mundo social. O modelo também dá conta da fluidez ou da instabilidade das identidades, na medida em que elas podem mudar de grupo a partir da asserção de um termo, negação dele e asserção do outro. Os pontos do quadrado são fixos; já a circulação pelos semantismos de gênero é dinâmica.

O quadrado permite ainda verificar como se estabelecem relações de poder entre as identidades, não pelo que elas são em si, mas pela posição que ocupam em relação aos termos simples, por sua vez valorados positiva ou negativamente de acordo com a axiologia do texto. É isso que está na base, por exemplo, da observação de Connell (1997) de que a violência contra homens gays deve-se especialmente à presença neles de figuras do feminino, pois o feminino é comumente disfórico na episteme das sociedades ocidentais.

Ter clara a distribuição de masculino e feminino em cada texto, identidade ou prática social, e observar a valoração de cada um dos termos no todo de sentido estudado permite apreender com mais efetividade não apenas o que ou quem é disfórico, mas o porquê dessa disforia. Essa apreensão é fundamental, dentre outras operações, nas análises que buscam sustentar iniciativas contra a discriminação de gênero nos âmbitos educacionais, políticos e da comunicação.

\section{Para finalizar: o que é, o que não é}

Este artigo apresentou um modelo teórico-metodológico para a análise de gênero, buscando responder a desafios de dois campos de estudos: de um lado, uma certa domesticação dos estudos de gênero, que a semiótica poderia contribuir para neutralizar; de outro, mostrar que, ao contrário do que se pensa, a semiótica pode dar conta das relações de poder baseadas no gênero.

Para mostrar a pertinência do modelo, o trabalho discutiu operações de categorias de gênero e sexualidade realizadas na semiótica por Greimas e Rastier e por Floch. Os autores elaboraram tais quadrados para ilustrar o funcionamento da lógica da estrutura fundamental de significação; ou seja, eles não estavam fazendo estudos de gênero. As críticas às operações mostram justamente a produtividade do instrumento, na medida em que acolhe concepções de gênero e suas relações de poder em sua variação no tempo e em cada texto que venha a ser analisado. Se há uma "violência semântica" percebida na proposição dos semioticistas, é porque tais concepções sofreram mudanças desde então, assim como os textos analisados. O modelo, no entanto, permanece válido. 
Os exemplos de operação do quadrado do gênero mostram uma análise dessa categoria que considera a diferença de valor de cada elemento - masculino e feminino - em textos distintos e que evita a armadilha da classificação prévia, o que constituiria a falha da análise de discurso do gênero. Para algumas correntes dos estudos de gênero, tais classificações podem ser problemáticas mesmo quando operadas para responder às legítimas demandas de representatividade sociopolítica das identidades divergentes, na medida em que acabariam reforçando procedimentos de discriminação e a lógica do binarismo de gênero.

O modelo também permite colocar em prática o princípio do gênero como construção discursiva, na medida em que masculino e feminino são tratados como temas formados por figuras de conteúdo e de expressão. Aspectos que definem o que é masculino ou feminino variam entre épocas, culturas, etnias, classes sociais; o modelo acolhe essa variação e desvela as valorações em cada texto, discurso ou prática.

$\mathrm{Na}$ medida em que mesmo as características corporais são tidas como figuras, o modelo pode considerar aspectos físicos sexualizados como integrantes do masculino ou do feminino, mas sem que determinem previamente uma identidade. Isso é útil para a apreensão da produção de sentido de identidades divergentes como as apresentadas no artigo, e que são apenas exemplos da diversidade efetivamente existente na macrossemiótica do mundo natural.

Tal diversidade, mesmo que questione ou negue o binarismo de gênero, baseiase nessa categoria semântica para sua expressão e autodefinição. O modelo, portanto, não traz o masculino e o feminino como identidades fixas e estáveis, mas como temas cujas figuras são combinadas nas identidades. Isso se deve ao fato de que se encontra a configuração de gênero em qualquer forma de divisão do mundo social e em qualquer unidade de análise selecionada.

Também é importante dizer o que este modelo não é: ele não é uma grade, como outras já existentes, que pretende classificar e circunscrever as identidades. O modelo pode ser operado na análise de discursos, textos e práticas que necessitem considerar uma abordagem de gênero, mas que entendam a não pertinência de se adotar denominações prévias. Situar identidades como bigêneras, agêneras, superfemininas ou supermasculinas é fazer a leitura semiótica dessas identidades como enunciados, dizendo como masculino e feminino nelas se articulam para a produção de sentido, e observar também a valoração positiva e negativa que nelas se opera.

Por fim, a ambição que este modelo oculta é a de que ele se torne anacrônico e inútil, o que ocorrerá quando não mais existir uma dicotomia de gênero a justificar desigualdades, violências e perda de direitos de toda ordem. Enquanto isso não acontece, contento-me que ele seja proveitoso em investigações que busquem apreender o funcionamento desses mecanismos. 
Adriana Tulio Baggio é pesquisadora independente em Curitiba. É publicitária, mestre em Letras (UFPB) e doutora em Comunicação e Semiótica (PUC-SP), com pósdoutorado em Tecnologia e Sociedade (UTFPR). Integra o Centro de Pesquisas Sociossemióticas (PUC-SP).

atbaggio@gmail.com

\section{Referências}

BAGGIO, A. T. Proposition d'un modèle sémiotique pour les études de genre. In: BERTRAND, D. et al. (coord.). Greimas aujourd'hui: I'avenir de la structure. Actes du congrès de l'Association Française de Sémiotique. Paris: AFS Éditions, 2019. Disponível em: http://afsemio.fr/publications/ greimas-aujourdhui-lavenir-de-la-structure-actes-du-congres-de-lafs-2017/. Acesso em: 22 Abr. 2020.

BRANNON, R. The Male Sex Role: Our Culture's Blueprint of Manhood, and What it's Done for us Lately. In: DAVID, D. S.; BRANNON, R. (org.). The Forty-Nine Percent Majority: The Male Sex Role. Reading: Addison-Wesley, 1976.

BUTLER, J. Problemas de gênero: feminismo e subversão da identidade. Tradução Renato Aguiar. Rio de Janeiro: Civilização Brasileira, 2003.

CONCHITA. Bio. Conchita, Vienna, 2017. Disponível em: http://conchitawurst.com/index.php?id=3. Acesso em: 4 dez 2017.

CONCHITA Wurst. Biography. Conchita Wurst, Viena, 2019. Disponível em: http://conchitawurst. com/about-us/. Acesso em: 12 fev. 2020.

CONNELL, R. W. La organización social de la masculinidad. In: VALDÉS, T.; OLAVARRÍA, J. (org.). Masculinidad/es: poder y crisis. Santiago: Isis Internacional/Flacso Chile, Ediciones de Las Mujeres, n. 24, 1997.

FIORIN, J. L. Elementos de análise do discurso. São Paulo: Contexto, 2000.

FLOCH, J. M. Quelques concepts fondamentaux en sémiotique générale. In: Petites mythologies de I'œil et de l'esprit: pour une sémiotique plastique. Paris, Amsterdam: Éditions Hadès-Benjamins, 1985.

FRANKLIN, S.; LURY, C.; STACEY, J. Feminism and cultural studies: pasts, presents, futures. In: STORY, J. (org.). What is Cultural Studies? A Reader. New York: Arnold, 1997. Disponível em: https://uniteyouthdublin.files.wordpress.com/2015/01/john_storey_what_is_cultural_studies_a_ readerbookzz-org.pdf. Acesso em: 12 Fev. 2020.

GREIMAS, A. J.; RASTIER, F. O jogo das restrições semióticas. In: GREIMAS, A. J. Sobre o sentido: ensaios semióticos. Tradução Ana Cristina Cruz Cesar e outros. Petrópolis: Vozes, 1975.

KILLERMANN, S. Genderbread Person v4.0: A teaching tool for breaking the big concept of gender down into bite-sized, digestible pieces. In: The Genderbread Person. Austin, 2017. Disponível em: https://www.genderbread.org. Acesso em: 12 Fev. 2020.

LA (NON)-REPRÉSENTATION de la non-binarité dans les médias. La vie en queer, 6 maio 2018. Disponível em: https://lavieenqueer.wordpress.com/2018/05/06/la-non-representation-de-la-nonbinarite-dans-les-medias/. Acesso em: 12 Fev. 2020.

LANZ, L. O corpo da roupa: a pessoa transgênera entre a transgressão e a conformidade com as normas de gênero. Uma introdução aos estudos transgêneros. Curitiba: Transgente, 2015.

MURARO, R. M. Introdução - Acerca do conceito de gênero. In: PUPPI, A. B.; MURARO, R. M. (org.). Mulher, gênero e sociedade. Rio de Janeiro: Relume Dumará/Faperj, 2001. 
STRATHERN, M. O gênero da dádiva: problemas com as mulheres e problemas com a sociedade na Melanésia. Tradução André Villalobos. Campinas: Editora da Unicamp, 2006.

VITTAR, P. Pabllo Vittar: "Sou um menino gay. Não sou trans e não faria cirurgia de redesignação sexual". Glamour, 11 Ago. 2017. [Entrevista cedida a] Flávia Bezerra. Disponível em: http:// revistaglamour.globo.com/Lifestyle/Must-Share/noticia/2017/08/pabllo-vittar-sou-um-menino-gaynao-sou-trans-e-nao-faria-cirurgia-de-redesignicao-sexual.html. Acesso em: 4 Dez. 2017.

Artigo recebido em 18/02/2020

e aprovado em 22/04/2020. 